\title{
Analisa Struktur Morfologi Pellet Semikonduktor ZnO terhadap Variasi Beban Kompaksi
}

\author{
(Morphological Structure Analysis of ZnO Semiconductor Pellet with Variations of \\ Compaction Load) \\ Yudit Cahyantoro NS ${ }^{\mathrm{a}}$, Agus Kurniawan ${ }^{\mathrm{b}}$, Bayu Prabandono ${ }^{\mathrm{c}}$ \\ ${ }^{a, b, c}$ Program Studi Teknik Perancangan Mekanik dan Mesin, Politeknik ATMI Surakarta \\ JI Mojo No 1, Surakarta, Indonesia \\ Telepon. $0271-714466$ \\ e-mail: yudit_cns@yahoo.com ${ }^{\mathrm{a}}$, agus_anggit@yahoo.co.id ${ }^{\mathrm{b}}$, bayuprabandono@gmail.com ${ }^{\mathrm{c}}$
}

\begin{abstract}
Abstrak
Salah satu proses yang penting dalam pembuatan bahan berbentuk pellet adalah proses kompaksi. Penelitian ini mempelajari struktur morfologi bahan semikonduktor $\mathrm{ZnO}$ yang dikompaksi dengan tekanan berbeda. Bahan awal adalah $\mathrm{ZnO}$ murni yang digiling dengan agate mortar, disaring dan dipadatkan dengan tekanan 10 bar, 20 bar dan 30 bar sehingga berbentuk pelet. Ukuran pelet adalah $\varnothing 13 \times 2 \mathrm{~mm}$. Selanjutnya, pelet ini disinter pada temperatur $1300^{\circ} \mathrm{C}$ dan kemudian diuji dengan menggunakan scanning microscope electron (SEM). Hasil pengujian menunjukkan bahwa struktur morfologi partikel material semikonduktor $\mathrm{ZnO}$ yang dikompaksi dengan tekanan 30 bar memiliki struktur morfologi yang tidak beraturan dan tidak terlihat batas butirnya. Ketika material tersebut dikompaksi, ruang antar butir menjadi sangat kecil dan tidak mampu menampung pembesaran partikel akibat proses sintering sehingga kelihatan menyatu dan menjadi keras. Oleh karena itu, semakin besar tekanan kompaksi maka struktur morfologi dari suatu partikel menjadi lebih padat dan menyatu. Namun demikian, besarnya tekanan kompaksi harus diperhatikan dengan mempertimbangkan kemampuan gaya tekan dari cetakan yang digunakan.
\end{abstract}

Kata Kunci: semikonduktor ZnO, pellet, Kompaksi, SEM

\begin{abstract}
One important process in manufacturing pellet material is a compaction. This research will study the morphological structure of $\mathrm{ZnO}$ semiconductor material that is compacted with different pressure. The first material is pure $\mathrm{ZnO}$ which was rinded with agate mortar, filtered and compacted with pressure of 10 bar, 20 bar and 30 bar so the pellet form were shaped. The size of pellet was $\varnothing$ $13 \times 2 \mathrm{~mm}$. Furthermore these pellet was sintered at temperature $1300^{\circ} \mathrm{C}$ and than tested by scanning electron microscope testing (SEM testing). The test results show that the morphological structure of a particle $\mathrm{ZnO}$ semiconductor material which was compacted at a pressure of 30 bar had an irregular morphological structure and no visible grain boundaries. When material was compacted, the space between the grains becomes very small and was unable to accommodate the enlargement of particles due to the sintering process so that it appears to fuse and become hard. Therefore, the greater the compacting pressure, the morphological structure of a particle becomes more dense and fuse. However, the magnitude of compacting pressure must be considered by considering the ability of the compressive force of the mold used.
\end{abstract}

Keywords: ZnO Semiconductor, Pellet, Compaction, SEM 


\section{Pendahuluan}

Beberapa peneliti telah melakukan penelitian proses manufaktur semikonduktor $\mathrm{ZnO}$ baik yang tipe-n maupun tipe-p sehingga menghasilkan semikonduktor $\mathrm{ZnO}$ yang stabil. Para peneliti memberikan material doping pada semikonduktor $\mathrm{ZnO}$ untuk mendapatkan karakteristik material yang diinginkan. Material doping yang diberikan antara lain lithium ( $\mathrm{Li})$ nitrogen $(\mathrm{N})$, galium $(\mathrm{Ga})$, copper $(\mathrm{Cu})$, phosporus $(\mathrm{P})$, arsenic $(\mathrm{Ar})$ [1], kalium $(\mathrm{L})$, mangan oksida (MgO) [2]. Untuk mengabungkan material doping dengan material semikonduktor $\mathrm{ZnO}$ diperlukan proses manufaktur.

Material $\mathrm{ZnO}$ sendiri memiliki wide band gap yang cukup besar $(3,37 \mathrm{eV})$, tahan temperatur tinggi dan ramah lingkungan [3], [4] dan material ZnO yang murni merupakan material semikonduktor tipe-n [5]. Material $\mathrm{ZnO}$ ini telah digunakan dalam berbagai aplikasi harvesting energy antara lain Dye Sensitized Solar Cell (DSSC) [6], [7], piezoelektrik [8] dan termoelektrik [9]. Satu material semikonduktor oksida yang menarik untuk diteliti sebagai material termoelektrik adalah material semikonduktor $\mathrm{ZnO}$.

Proses manufaktur semikonduktor $\mathrm{ZnO}$ kebanyakan menghasilkan bentuk thin film. Metode pembuatan thin film telah dilakukan dengan berbagai macam metode antara lain metode mechanical alloys-kompaksi-sintering-pulse laser deposition (PLD) [2] dan metode RF-magnetron sputtering [10]. Sedangkan metode manufaktur material ZnO berbentuk pellet antara lain metode mechanical alloys-kalsinasi-kompaksi-sintering [9],11] metode sol gel, method - dikeringkan - sintering - anilling dalam kondisi gas Ar-kompaksi [12] dan metode magnetic stirring-dikeringkan-kalsinasi-kompaksi-sintering [13]. Dari semua metode yang digunakan, satu proses yang penting adalah kompaksi. Proses kompaksi digunakan untuk membuat thin film dan pellet.

Beberapa metode kompaksi yang telah dilakukan dalam proses penelitian antara lain proses kompaksi dengan menggunakan sledgehammer pada material natural clay [14], static dan modified proctor pada material pecahan batu dengan tekanan $4000 \mathrm{kPa}$ sampai $12000 \mathrm{kPa}$ [15], metode spark plasma sintering dengan tekanan $50 \mathrm{Mpa}$ untuk material semikonduktor Ag-Pb-Sb-Te [16], metode cold isotactic press (CIP) dengan tekanan 2000 bar pada material semikonduktor $\mathrm{Ca} 3 \mathrm{Co} 4 \mathrm{O} 9$ dan (ZnO)7Ln2O3 [9], metode CIP sebesar 2 Mpa pada material Al doped ZnO [13], metode rotary tablet press (R190 FT, GEA-Courtoy, Belgium) dengan tekanan 20, 30 dan $40 \mathrm{Mpa}$ dengan material lactose, mannitol, sugar cores [17] dan metode cold compaction pada material semikonduktor $\mathrm{ZnO}$ yang didoping $\mathrm{Cu}$ dengan tekanan 70 bar [18]. Penelitian terhadap proses kompaksi pada material semikonduktor $\mathrm{ZnO}$ belum banyak yang melakukan.

Tujuan penelitian ini adalah untuk menganalisa struktur morfologi material semikonduktor $\mathrm{ZnO}$ yang telah kompaksi menggunakan metode yang sederhana yaitu cold single compaction pada variasi tekanan yang tidak besar 10, 20 dan 30 bar. Ukuran material yang dihasilkan $\varnothing 13 \times 2 \mathrm{~mm}$. Struktur morfologinya diuji dengan menggunakan pengujian scanning electron microscope (SEM).

\section{Metode}

Metode penelitian yang digunakan adalah metode studi eksperimental dengan menganalisa struktur morfologi semikonduktor $\mathrm{ZnO}$ yang berbentuk pellet. Material Semikonduktor $\mathrm{ZnO}$ (99.9\%) dari merck dihancurkan dengan agate mortar dan diayak dengan ayakan yang memiliki mesh 200 dan hasilnya berupa serbuk yang halus. Serbuk tersebut selanjutnya dicampur dengan ethanol sebanyak $4 \%$ dan dipress menggunakan mesin press hidrolik dengan variasi tekanan 10, 20 dan 30 bar menjadi pellet berukuran $\varnothing$ $13 \times 2 \mathrm{~mm}$.

Selanjutnya material disintering pada temperatur $1300^{\circ} \mathrm{C}$ dengan range kenaikan $100^{\circ} \mathrm{C} /$ menit selama 2 jam. Selesai disintering, pellet tersebut diuji morfologinya dengan pengujian SEM dengan menggunakan mesin SEM-FEI Inspect-S50. Diagram alir metodologi penelitian yang dilakukan dapat dilihat pada

Gambar 3.1.

\section{Hasil dan Pembahasan}

Material semikonduktor $\mathrm{ZnO}$ telah diberi perlakuan kompaksi dengan variasi dan tekanan 10,20 da 30 bar serta disintering $1300^{\circ} \mathrm{C}$ telah berhasil dibuat. Kemudian, material 
tersebut diuji kekerasannya dengan diuji morfologinya dengan menggunakan mesin SEMFEI Inspect-S50. Hasil pengujiannya dapat dilihat pada Gambar 3.

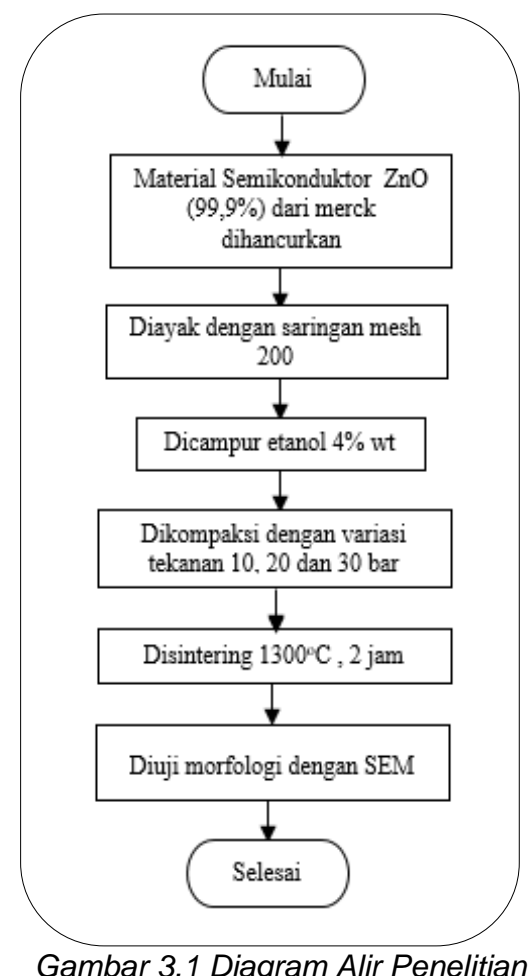

Gambar 3. menunjukkan material semikonduktor yang dikompaksi 10 bar [Gambar 3. (a)] memiliki butiran-butiran partikel yang baik dan rata-rata besarnya hampir sama. Batas butir antar partikelnya masih terlihat sangat jelas sehingga antara partikel masih dapat terlepas jika mendapat tekanan atau hentakan. Material semikonduktor yang dikompaksi 20 bar [Gambar 3. (b)] memiliki butiran-butiran partikel yang mulai tidak teratur. Batas butir antar partikelnya masih terlihat sangat jelas namun sudah tidak terlihat rata lagi partikelnya. Jumlah batas butirnya lebih sedikit dengan area yang sama. Material semikonduktor yang dikompaksi 30 bar [Gambar 3. (c)] memiliki butiran-butiran partikel tidak teratur dan tidak jelas bentuknya. Batas butir antar partikelnya sudah hampir tidak terlihat lagi. Hal ini menunjukkan antar partikel sudah menyatu dan sangat rapat.
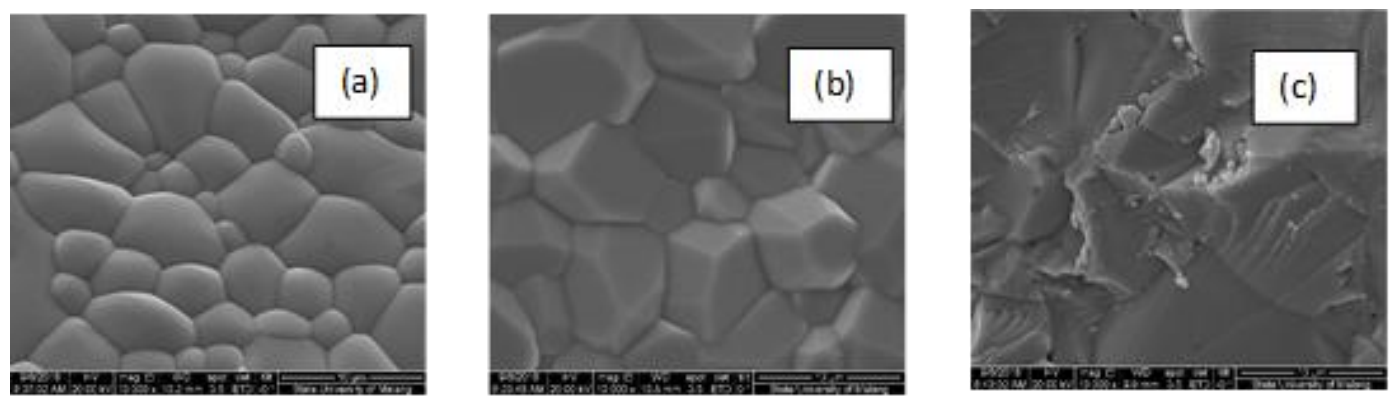

Gambar 3. 2 Hasil pengujian SEM (a) 10 bar (b) 20 bar (c) 30 bar.

Suatu material semikonduktor di dalamnya terdiri dari butiran - butiran partikel. Ketika material semikonduktor $\mathrm{ZnO}$ dikompaksi, butiran partikel yang di dalamnya akan memadat. Semakin besar tekanan kompaksi yang diberikan, maka butiran partikel yang ada di dalam material tersebut akan semakin padat sehingga ruang antar butirannya menjadi kecil dibandingkan dengan material yang tidak dipadatkan. Semakin besar tekanan kompaksi 
yang diberikan, kemungkinan jarak antar butirannya akan semakin rapat sehingga ruang antar butirannya semakin kecil. Selanjutnya, setelah material semikonduktor $\mathrm{ZnO}$ tersebut disintering dengan temperatur $1300^{\circ} \mathrm{C}$. Material yang disintering butiran - butirannya akan membesar. Butiran - butiran yang membesar ini membutuhkan ruang untuk pembesarannya tersebut. Dikarenakan material tersebut dipadatkan, maka ruang antar butiran menjadi kecil menyebabkan butiran partikel yang membesar tersebut saling menyatu dikarenakan kecilnya ruang antar butiran. Hal ini terlihat pada Gambar 3. dimana material yang dikompaksi 10 bar masih terlihat jelas batas antar butirnya dibandingkan dengan yang dikompaksi 30 bar. Hal ini menunjukkan semakin besar tekanan kompaksi pada suatu material, maka partikel didalammya akan semakin rapat dan batas butirnya akan semakin sedikit sehingga kemungkinan material tersebut menjadi lebih keras. Analisa struktur morfologi ini sesuai dengan penelitian yang dilakukan oleh Kurniawan dkk [19] terkait nilai kekerasan semikonduktor $\mathrm{ZnO}$ yang di kompaksi dengan tekanan yang berbeda - beda. Hasil penelitian ini menunjukkan nilai kekerasan material semikonduktor $\mathrm{ZnO}$ yang dikompaksi 30 bar memiliki nilai kekerasan mikro vikers terbesar dengan nilai rata-rata kekerasannya sebesar $213.85 \mathrm{Hv}$ [19].

\section{Kesimpulan}

Material pellet semikonduktor $\mathrm{ZnO}$ dengan variasi kompaksi 10 bar, 20 bar dan 30 bar dan disintering pada temperatur $1300^{\circ} \mathrm{C}$ telah berhasil dibuat. Material yang dikompaksi 30 bar dan disintering $1300^{\circ} \mathrm{C}$ memiliki butiran-butiran partikel tidak teratur dan tidak jelas bentuknya sehingga terlihat antar butiran partikelnya telah menyatu. Batas butir antar partikelnya hampir tidak terlihat lagi. Hal ini menunjukkan butiran partikel yang satu dengan yang lain sudah menyatu dan sangat rapat yang dikarenakan ketika dikompaksi ruang antar butir menjadi sangat kecil dan tidak mampu menampung pembesaran butiran partikel akibat proses sintering sehingga butiran - butiran partikel tersebut kelihatan menyatu dan material itu menjadi keras. Oleh karena itu dapat disimpulkan, semakin besar tekanan kompaksi dalam pembuatan pellet berbahan material semikonduktor, maka jarak antara butiran partikel didalammya akan semakin rapat dan ruang antar butiran partikel menjadi lebih kecil dan rapat sehingga kemungkinan besar material tersebut menjadi keras.

\section{Daftar Pustaka}

[1] A. Janotti, "Fundamental of Zinc Oxide as A Semiconductor," Rep. Prog. Phys., vol. 126501, p. 29, 2009.

[2] L. Zhang, Z. Ye, J. Huang, B. Lu, H. He, J. Lu, et al., "Fabrication and Propeties of ptype K Doped Zn1-xMgxO Thin Film," Journal of Alloys and Compounds, vol. 509, pp. 7405-7409, 2011.

[3] J. W. Fergus, "Oxide materials for high temperature thermoelectric energy conversion," Journal of the European Ceramic Society, vol. 32, pp. 525-540, 2012.

[4] I. S. Kim, E.-K. Jeong, D. Y. Kim, M. Kumar, and S.-Y. Choi, "Investigation of p-type behavior in Ag-doped ZnO thin films by E-beam evaporation," Applied Surface Science, vol. 255, pp. 4011-4014, 2009.

[5] K. Cheng, Q. Li, J. Meng, X. Han, Y. Wu, S. Wang, et al., "Interface engineering for efficient charge collection in $\mathrm{Cu} \mathrm{O} / \mathrm{ZnO}$ heterojunction solar cells with ordered $\mathrm{ZnO}$ cavity-like nanopatterns," Solar Energy Materials \& Solar Cells, vol. 116, pp. 120-125, 2013.

[6] E. Hosono, S. Fujihara, I. Honma, and H. Zhou, "The Fabrication of an Upright-Standing Zinc Oxide Nanosheet for Use in Dye-Sensitized Solar Cells," Advances Materials, vol. 17, pp. 2091-2094, 2005.

[7] K. E. Kim, S.-R. Jang, J. Park, R. Vittal, and K.-J. Kim, "Enhancement in the performance of dye-sensitized solar cells containing $\mathrm{ZnO}$-covered $\mathrm{TiO} 2$ electrodes prepared by thermal chemical vapor deposition," Solar Energy Materials \& Solar Cells, vol. 91, pp. 366-370, 2007.

[8] S. Dai, M. L. Dunn, and H. S. Park, "Piezoelectric constants for $\mathrm{ZnO}$ calculated using classical polarizable core-shell potentials," Nanotechnology, vol. 21, pp. 1-8, 2010. 
[9] S.-M. Choi, K.-H. Lee, C.-H. Lim, and W.-S. Seo, "Oxide-based thermoelectric power generation module using p-type $\mathrm{Ca}_{3} \mathrm{Co}_{4} \mathrm{O}_{9}$ and n-type $(\mathrm{ZnO})_{7} \mathrm{In}_{2} \mathrm{O}_{3}$ legs," Energy Conversion and Management, vol. 52, pp. 335-339, 2010.

[10] K. Kobayashi, T. Koyama, X. Zhang, Y. Kohono, Y. Tomita, Y. Maeda, et al., "Preparation of p-type ZnO Films by Alternate Deposition of $\mathrm{ZnO}$ and Mg3N2 Films," Procedia Engineering, vol. 36, pp. 427-433, 2012.

[11] L. Han, Y. Jiang, S. Li, H. Su, X. Lan, K. Qin, et al., "High temperature thermoelectric properties and energy transfer devices of $\mathrm{Ca}_{3} \mathrm{Co}_{4-\mathrm{x}} \mathrm{Ag}_{\mathrm{x}} \mathrm{O}_{9}$ and $\mathrm{Ca}_{1-\mathrm{y}} \mathrm{Sm}_{\mathrm{y}} \mathrm{MnO}_{3}$," Journal of Alloys and Compounds, vol. 509, pp. 8970-8977, 2011.

[12] C. Li, J. Lv, and Z. Liang, "Effects of Al doping on the optical and electrical properties of pre-synthesized ZnO powders by solid state method," Journal Material Science, vol. 23, pp. 1673-1677, 2012.

[13] X. Qu, W. Wang, S. Lv, and D. Jia, "Thermoelectric properties and electronic structure of Al-doped ZnO," Solid State Communications, vol. 151, pp. 332-336, 2011.

[14] J. Chen, H. Wang, and Y. Yao, "Experimental Study of Nonlinear Ultrasonic Behavior of Soil Materials During the Compaction " Ultrasonics, vol. 5229, pp. 1-6, 2016.

[15] E. Yaghoubi, M. M. Disfani, A. Arulrajah, and J. Kodikara, "Impact of Compaction Methods on Resilient Response of Unsaturated Granular Pavement Material," Procedia Engineering, vol. 143, pp. 323-330, 2016.

[16] L. Goncalves, J. G. Rocha, C. Couto, P. Alpuim, GaoMin, D. M. Rowe, et al., "Fabrication of flexible thermoelectric microcoolers using planar thin-film technologies," Journal Of Micromechanics And Microengineering, vol. 17, pp. 168-173, 2007.

[17] M. Xu, P. W. S. Heng, and C. V. Liew, "Formulation and Process Strategies to Minimize Coat Damage for Compaction of Coated Pellets in a Rotary Tablet Press: A Mechanistic View," International Journal of Pharmaceutics, vol. 499, pp. 29-37, 2016.

[18] A. Kurniawan, S. Hadi, Z. Arifin, Ubaidillah, and Suyitno, "Effect of Sintering Temperature to The Thermal Conductivity of $\mathrm{Cu}$ doped $\mathrm{ZnO}$," presented at the The $1^{\mathrm{st}}$ International Conference on Engineering Technology and Industrial Application, Surakarta, 2014.

[19] A. Kurniawan, B. Prabandono, and Sularman, "Studi Eksperimental Nilai Kekerasan Semikonduktor ZnO terhadap Variasi Beban Kompaksi " POLITEKNOSAINS, vol. XV, pp. 30-35, 2016. 